\title{
АРТ-ТЕРАПИЯ КАК МЕТОД КОРРЕКЦИИ ТРЕВОЖНОСТИ СТАРШЕКЛАССНИКОВ В ПЕРИОД ПОДГОТОВКИ К ЕГЭ'
}

\section{ART THERAPY AS A METHOD OF CORRECTING HIGH SCHOOL STUDENTS' ANXIETY IN PREPARATION FOR THE UNIFIED STATE EXAM}

\section{Novikova N. Shcherbakova}

Summary: The article presents material on the study of the possibility of art therapy as a method of correcting the anxiety of high school students before the unified state exam. The characteristic of youth age is given, since the youth period itself acts as a critical difficult stage in the life of every high school student. They are faced with a lot of difficult tasks: successfully passing exams, choosing and entering a higher education institution, which entails drastic changes in life - a change of the team and the beginning of the path to independent life.

The influence of exam anxiety on the mental state of a high school student, as well as on the overall success of exams, is considered. It is shown that during this period, the level of stress and anxiety of high school students increases significantly, which can lead to harmful consequences. And in order for a student to successfully pass all the exams, he needs support and help from others. This is the only way a high school student can be self-confident, be motivated to work, and not feel a constant sense of fear and anxiety. The experiment conducted in the course of the study proves that the method of art therapy in training is effective for high school students to correct anxiety during the exam period.

Keywords: anxiety, school anxiety, correction, unified state exam, high school student, art therapy.
ФГБОУ ВО «Пензенский государственный университет» masha.n1997@mail.ru

Щербакова Наталья Евгеньевна

к.n.н., доцент, ФГБОУ ВО «Пензенский государственный университет»

stenyakova-n@mail.ru

Аннотация: В статье представлен материал по исследованию возможности арт-терапии как метода коррекции тревожности старшеклассников перед единым государственным экзаменом. Дана характеристика юношескому возрасту, так как юношеский период сам по себе выступает в роли переломного сложного этапа в жизни каждого старшеклассника. Перед ними ставится множество трудновыполнимых задач: успешная сдача экзаменов, выбор и поступление в высшее учебное заведение, что влечет за собой кардинальные изменения в жизни - смена коллектива и начало пути к самостоятельной жизни.

Рассмотрено влияние экзаменационной тревожности на психическое состояние старшеклассника, а также в целом на успешность сдачи экзаменов. Показано, что в этот период уровень стресса и тревоги старшеклассников в разы возрастает, что может привести к пагубным последствиям. А для того, чтобы ученик успешно сдал все экзамены, ему необходима поддержка и помощь со стороны окружающих. Только так старшеклассник сможет быть уверенным в себе, быть мотивированным к деятельности и не испытывать постоянное чувство страха и тревоги. Проведенный в ходе исследования эксперимент доказывает, что метод арт-терапии в тренинге является эффективным для старшеклассников по коррекции тревожности в период сдачи экзамена.

Ключевые слова: тревожность, тревога, школьная тревожность, коррекция, единый государственный экзамен, старшеклассник, арт-терапия.

вых личностных качеств и относился ко всему критично. Только теперь на плечи юноши возлагается большая ответственность и повышается требовательность к нему. В большинстве случаев старшеклассники не готовы к таким переменам. В 11 классе для них остро встает вопрос о дальнейшем обучении, самоопределении, то есть о поступлении в вуз. А для того, чтобы поступить, старшеклассникам необходимо сдать единый государственный экзамен (ЕГЭ). В выпускном классе почти для всех учеников это является главной причиной их переживания и тревоги. Этому способствует множество факторов. Такие, как давление и большая требовательность со стороны родителей, негативный 
настрой учителей (зачастую учителя преувеличивают важность и сложность данных экзаменов и негативно настраивают учеников), а также неуверенность в собственных силах.

В этот возрастной период особенно важным для старшеклассников является поддержка и понимание со стороны родителей и близких. Старшеклассники должны быть уверены в том, что они не одни, что в них верят и поддерживают. Иначе их уровень тревоги может возрасти до очень высокого, неконтролируемого. Именно поэтому на данном возрастном этапе необходимым является проведение различного рода занятий, тренингов, особенно арт-терапевтических, направленных на коррекцию тревожности старшеклассников перед ЕГЭ.

Метод арт-терапии направлен на гармонизацию психического состояния путем развития способности самовыражения и самопознания. В повседневной жизни мы все ограничены строгими рамками, действуем по какому-либо заданному плану. И порой нам трудно бывает разобраться в самих себе, понять, что происходит внутри нас, чем вызвано то или иное состояние, например, той же самой тревоги. Но стоит нам попробовать метод арттерапии, как сразу же все раскладывается по полочкам. Мы даем волю нашему бессознательному, волю нашим чувствам и действиям. Что в свою очередь приводит нас в состояние гармонии и умиротворенности. Теперь уже человек способен взглянуть на свою проблему с другой стороны и понять, что ее решение и преодоление ему по силам.

Для проверки гипотезы о том, что специально разработанная коррекционная программа, которая содержит в себе методы арт-терапии, способствует снижению уровня тревожности старшеклассников перед ЕГЭ, было проведено исследование на базе МБОУ СОШ №63 г. Пензы. В исследовании приняли участие 58 учеников 11 класса в возрасте 16-17 лет. Исследование проводилось с полного согласия испытуемых.

На первом этапе исследования изучались школьный, самооценочный и межличностный уровни тревожности старшеклассников с помощью методики «Шкала тревожности» Кондаша.

Цель методики: диагностика уровня тревожности по школьной, самооценочной и межличностной шкале.

На втором этапе исследования выявлялись реактивный и личностный уровни тревожности с помощью опросника Спилбергера-Ханина для определения ситуативной и личностной тревожности.

Цель методики: определение уровня реактивной и личностной тревожности.
На следующем этапе диагностики было проведено анкетирование учащихся с целью выявления их уровня знакомства с процедурой, уровня тревоги, вызванной предстоящими экзаменами, а также был выявлен уровень владения навыками самоконтроля.

Для того, чтобы определить уровень готовности учеников выпускного класса к ЕГЭ по нескольким параметрам, испытуемым было предложено заполнить анкету, где они должны были оценить свое согласие или несогласие с некоторыми утверждениями по 10-балльной шкале.

Данная анкета позволила нам определить уровень готовности учащихся к ЕГЭ по нескольким параметрам. Она имеет ориентировочный характер, позволяет оценить готовность к ЕГЭ глазами самих выпускников и имеет следующие составляющие: способность к самоорганизации (познавательный компонент), уровень тревоги (личностный компонент) и знакомство с процедурой экзамена (процессуальный компонент). Анкета может проводиться для скрининговой диагностики в выпускных классах, а также для оценки результативности деятельности психолога (в этом случае она проводится до и после занятий). Опыт работы с анкетой показывает, что во втором случае показателем эффективности не обязательно будет являться рост показателей. Напротив, зачастую в результате занятий дети осознают дефицит знаний по той или иной проблеме, что и найдет отражение в снижении показателей.

Затем, после первичной диагностики, была проведена коррекционная работа с помощью метода арттерапии с учащимися, чей уровень тревожности оказался высоким.

Цель социально-психологического тренинга: снижение уровня тревожности старшеклассников перед ЕГЭ.

Задачи тренинга: создание доверительной обстановки в группе; отработка умения выражать свои эмоции и чувства, а также обсуждение их в группе; развитие образного мышления; активизация процесса самопознания; развитие навыка работы в команде; снижение уровня тревожности; закрепление полученных навыков.

Программа тренинга включает в себя следующие приемы: методы арт-терапии; работа с метафорическими картами; групповая дискуссия; игры (психогимнастические, целевые); приёмы саморегуляции.

Формы работы: групповая работа, работа в парах, работа в микро-группах.

Ожидаемым результатом социально-психологического тренинга является: снижение уровня тревожности 
старшеклассников.

Было проведено 8 тренинговых занятий, каждое из которых длилось 1 час.

На заключительном этапе исследования была осуществлена повторная диагностика учащихся, принимавших участие в тренинговых занятиях, а также были сравнены результаты до и после проведения коррекционной работы. Математическая обработка была выполнена с помощью t-критерия Стьюдента.

Ключевыми понятиями нашего исследования являются тревожность, юношеский возраст и метод арт-терапии для коррекции тревожности. Вначале проанализируем понятия «тревога» и «тревожность» в зарубежной и отечественной психологии.

В психологии тревожность понимается, как некое нервно-психическое напряжение, при котором обычная нейтральная ситуация воспринимается человеком, как угрожающая, вызывающая переживания. При этом данное состояние может сопровождаться такими чувствами, как страх, гнев и вина [1, с. 432].

Анализ современных психологических исследований тревожности приводит к заключению, что они исходят в основном из четырех основных источников: классических теорий эмоций, психоанализа, неофрейдизма и теории научения.

Дж. Тейлор был первым, кто дал определение тревожности, которое и на сегодняшний день используется многими специалистами. Тревожность в понимании автора - это переживание нейтральной ситуации как угрожающей и соответствующее этому поведенческое стремление избегания воображаемой угрозы.

Тревожность в отечественной психологии различается, как некое устойчивое свойство и как эмоциональное состояние, черта темперамента и личности. Эти различия соответствуют таким понятиям, как «тревога» и «тревожность». По мнению Ю.Л. Ханина, тревога как состояние - это реакция на социально-психологические факторы, вызывающие стресс. Данная реакция сопровождается беспокойством, напряжённостью, озабоченностью, а также активизацией вегетативной нервной системы. А тревожность характеризуется, как склонность индивида к переживанию тревоги. В этом случае у человека имеется большая вероятность возникновения реакции тревоги $[2$, с. 143].

Для дальнейшего исследования нам необходимо дать характеристику юношескому возрасту. Некоторые психологи в своей возрастной периодизации определяют подростковый возраст вплоть до 17-18 лет, кто-то счита- ет этот возраст ранним юношеством. Но в любом случае семнадцатилетний школьник ещё имеет общие черты с подростком. В своей работе мы ориентировались на возрастную периодизацию Д.Б. Эльконина, где границы ранней юности определены в возрасте 15-17 лет [3, с. 379].

Находясь в возрасте 16 лет, школьнику ещё сложно освободиться от своей подростковой односторонности в своих оценках и категоричности. Лица юношеского возраста чувствуют свою внутреннюю самостоятельность, их мысли устремлены в будущее, они стараются быть более уравновешены и общительны. Но при этом есть и обратная сторона. Старшеклассникам, окружающая их действительность порой кажется мрачной, негативной. Из-за этого уровень их мотивации в разы падает, в них начинает проявляться отчаяние и пессимизм. Здесь необходимо активное привлечение и включение лиц юношеского возраста в решение конкретной проблемы, вызывающей негативные переживания [4, с. 39].

В этот период необходимо отметить значимость ЕГЭ в жизни старшеклассников, поскольку экзамены оказывают на лиц юношеского возраста немалое психологическое влияние. Считается, что данное нововведение является эффективным в системе образования. Ведь ЕГЭ дает возможность ученикам сдать экзамены только в школе, не сдавая вступительные в институте. При этом выпускники могут подать свои документы сразу в несколько вузов. Но при этом существует мнение, что эта модернизация не способна в полной мере проверить истинные знания школьников. Помимо прочего ЕГЭ является причиной возникновения тревожности и других отрицательных проявлений у лиц юношеского возраста. Ведь для них это является очень важным. Поскольку от успешности сдачи экзаменов зависит их дальнейшая судьба. Данный вопрос волнует не только выпускников, но и их родителей, учителей и психологов. Ведь то, насколько успешно ученик сдаст экзамен, зависит не только от уровня его знаний, но и от его психоэмоционального состояния [6, с. 197-203].

Экзаменационную тревожность также называют ситуационной тревожностью, поскольку она проявляется только в определенной ситуации, в данном случае перед и во время экзамена. Выпускники лишены психологической поддержки во время экзамена, проверяют их работы и принимают решение совершенно незнакомые для них люди.

Необходимым является проводить адаптацию учащихся к сдаче ЕГЭ на протяжении всего обучения в школе. Но особенно стоит уделить внимание учебному году перед сдачей экзаменов. Все участники образовательного процесса должны способствовать благоприятному психологическому настрою выпускников. Поскольку частыми являются случаи стрессового состояния, нервно- 
го срыва и неадекватного поведения перед и вовремя ЕГЭ. Период юношеского возраста - очень важное время в жизни каждого молодого человека. На этом этапе лица юношеского возраста приобретают самостоятельность в некоторых решениях, выбирают свой дальнейший профессиональный путь, сдают ЕГЭ для поступления в ВУЗ. Иными словами говоря - переживают состояния тревоги и стресса. Именно поэтому требуется комплексная коррекция состояния тревоги, поддержка и помощь всем лицам юношеского возраста [7, с. 2834]. В настоящее время арт-терапия является эффективным методом коррекции и используется как самостоятельная или дополнительная техника.

Адриан Хилл ввел термин «арт терапия», что обозначает «терапия искусством». Впервые он применил этот термин, когда проводил терапевтическую работу с детьми больными туберкулезом. Под этим понятием он подразумевал любую коррупционную работу, в которой присутствуют элементы искусства.

3. Фрейд и К.Г. Юнг были первыми, кто написал об арт-терапии в своих теоретических идеях. В дальнейшем К. Роджерс и А. Маслоу продолжили развивать данную идею в своих гуманистических моделях развития личности [8, с. 64].

Главная цель метода арт-терапии - гармонизация развития личности путем развития способности самовыражения и самопознания. 3. Фрейд считал, что самым главным механизмом воздействия на человека в процессе коррекции методом арт-терапии является механизм сублимации. По мнению же К. Юнга, данный метод помогает человеку установить зрелый баланс между бессознательным и сознательным «Я» [9, с. 220].

Необходимо отметить, что одно из важных в методе арт-терапии, это столкновение между собой сознательного и бессознательного, а в дальнейшем их примирение. Все это осуществляется благодаря технике активного воображения.

Когда арт-терапия только начинала развиваться, считалось, что любой продукт творческой деятельности отражает бессознательную сторону человека, его неосознаваемые психические процессы [10, с. 256].

Таким образом, можно сделать вывод о том, что метод арт-терапии является благоприятным и подходящим для старших школьников, поскольку в процессе рисования учащийся способен реализовать себя, познать и выразить весь свой негатив в рисунке, с целью избавления от своих переживаний.

После первичной диагностики, нами было выявлено количество учащихся, имеющих высокий уровень тревоги по какому-либо из показателей методики (одной, двух или всех трех). Из 58 человек оказалось 18 учащихся с высоким уровнем тревоги, причем из них 17 девушек и всего лишь 1 юноша. Это может быть связано с тем, что для девушек характерны такие личностные особенности, как ответственность, исполнительность, более высокая критичность. Именно эти характеристики и способствуют более высокому развитию уровня тревожности.

После проведенной нами коррекционной работы, была осуществлена повторная диагностика участников тренинга.

Результаты, полученные по итогам методики «Шкала тревожности» Кондаша до и после коррекционного воздействия, представлены в таблице 1.

До тренинговых занятий для 40\% испытуемых было характерно «чрезмерное спокойствие» по общему уровню тревожности, после занятий этот процент понизился до 30\%. Но при этом данный результат будет являться положительным, так как «чрезмерное спокойствие» может негативно сказываться на результатах деятельности. Также при первичной диагностике

Таблица 1.

Результаты исследования по методике

«Шкала тревожности» Кондаша до и после коррекционного воздействия

\begin{tabular}{|l|c|c|c|c|c|c|c|c|}
\hline \multirow{2}{*}{$\begin{array}{c}\text { Уровень } \\
\text { тревожности }\end{array}$} & \multicolumn{2}{|c|}{$\begin{array}{c}\text { Общий уровень } \\
\text { тревожности }\end{array}$} & \multicolumn{2}{|c|}{ Школьная тревожность } & \multicolumn{2}{|c|}{$\begin{array}{c}\text { Самооценочная } \\
\text { тревожность }\end{array}$} & \multicolumn{2}{|c|}{$\begin{array}{c}\text { Межличностная } \\
\text { тревожность }\end{array}$} \\
\cline { 2 - 11 } & До & После & До & После & \multicolumn{2}{|l|}{ До } & После & \multicolumn{2}{|c|}{ До } & После \\
\hline $\begin{array}{l}\text { «Чрезмерное } \\
\text { спокойствие» }\end{array}$ & $40 \%$ & $30 \%$ & $0 \%$ & & $40 \%$ & $40 \%$ & $0 \%$ & $10 \%$ \\
\hline Нормальный & $60 \%$ & $70 \%$ & $80 \%$ & $90 \%$ & $60 \%$ & $50 \%$ & $60 \%$ & $80 \%$ \\
\hline $\begin{array}{l}\text { Несколько } \\
\text { повышенный }\end{array}$ & $0 \%$ & & $10 \%$ & $10 \%$ & $0 \%$ & $10 \%$ & $30 \%$ & $10 \%$ \\
\hline Высокий & $0 \%$ & & $10 \%$ & $0 \%$ & $0 \%$ & & $10 \%$ & $0 \%$ \\
\hline Ср. знач. & 42,5 & 34,125 & 11,4 & 8,25 & 13,2 & 11,75 & 17,9 & 14,125 \\
\hline
\end{tabular}


было обнаружено, что у $60 \%$ учеников общий уровень тревожности достигает нормального. После проведения тренингов данный процент учеников оказался равным 70\%. С помощью математической обработки данных не было выявлено различий (тэмпиическое $=0,9$ ).

До проведенных тренингов у 10\% учащихся был выявлен высокий уровень школьной тревожности. При повторной диагностике данный показатель оказался равным 0\%. Можно сказать о том, что имеется тенденция к снижению уровня тревожности. В случае проведения дальнейшей коррекционной работы с данной выборкой результаты будут более заметны. Но при математической обработке данных не было выявлено различий (t эмпирическое $=2,1$ ).

До коррекционных занятий у $60 \%$ старшеклассников уровень самооценочной тревожности оказался нормальным. После проведения коррекции этот процент снизился до 50\%. С помощью математической обработки данных не было выявлено различий ( $=2,1)$.

Также стоит отметить, что при первичной диагностике $30 \%$ старшеклассникам был характерен несколько повышенный уровень межличностной тревожности. После же проведения нами коррекционной работы, данный процент снизился до 10\%. Высокий уровень межличностной тревожности был обнаружен у $10 \%$ испытуемых при проведении диагностики до тренинговых занятий. При повторной диагностике этот показатель снизился до 0\%. Математическая обработка данных подтвердила выявленные различия на однопроцентном уровне значимости (

Результаты, полученные по итогам опросника Спилбергера-Ханина до и после коррекционного воздействия, представлены в таблице 2.

Таблица 2.

Результаты испытуемых по опроснику Спилбергера-Ханина для определения ситуативной и личностной тревожности до и после коррекционного воздействия

\begin{tabular}{|l|c|c|c|c|}
\hline \multirow{2}{*}{$\begin{array}{c}\text { Уровень } \\
\text { тревожности }\end{array}$} & \multicolumn{2}{|c|}{$\begin{array}{c}\text { Реактивная } \\
\text { тревожность }\end{array}$} & \multicolumn{2}{c|}{$\begin{array}{c}\text { Личностная } \\
\text { тревожность }\end{array}$} \\
\cline { 2 - 5 } & До & После & До & После \\
\hline Низкий & $80 \%$ & $90 \%$ & $0 \%$ & $50 \%$ \\
\hline Умеренный & $20 \%$ & $10 \%$ & $10 \%$ & $40 \%$ \\
\hline Высокий & $0 \%$ & $0 \%$ & $90 \%$ & $10 \%$ \\
\hline Ср. знач. & 27 & 26,6 & 49,3 & 27,7 \\
\hline
\end{tabular}

Низкий уровень реактивной тревожности был обнаружен у $80 \%$ учащихся до тренинговых занятий. После проведения тренингов данный процент увеличился до
90\%. Математическая обработка данных не подтвердила выявленные различия (

Умеренный уровень личностной тревожности был свойственен до коррекционной работы 10\% испытуемым, после - 40\%. 90\% старшеклассникам был свойственен до проведения тренингов высокий уровень личностной тревожности. После же проведения коррекционной работы данный процент учеников понизился до 10\%. Математическая обработка данных подтвердила выявленные различия на однопроцентном уровне значимости (

Результаты анкеты до и после коррекционного воздействия, представлены в таблице 3.

Таблица 3.

Результаты анкеты «Готовность к ЕГЭ» М.Ю.Чибисовой до и после коррекционного воздействия

\begin{tabular}{|c|c|c|c|c|c|c|}
\hline \multirow{3}{*}{$\begin{array}{c}\text { Уровень } \\
\text { Готовности }\end{array}$} & \multicolumn{6}{|c|}{ Параметры готовности } \\
\hline & \multicolumn{2}{|c|}{$\begin{array}{c}\text { Знакомство } \\
\text { с процедурой }\end{array}$} & \multicolumn{2}{|c|}{$\begin{array}{l}\text { Уровень } \\
\text { тревоги }\end{array}$} & \multicolumn{2}{|c|}{$\begin{array}{c}\text { Самоконтроль } \\
\text { и самоорганизация }\end{array}$} \\
\hline & До & После & До & После & До & После \\
\hline Низкий & $10 \%$ & $0 \%$ & $40 \%$ & $90 \%$ & $30 \%$ & $10 \%$ \\
\hline Высокий & $90 \%$ & $100 \%$ & $60 \%$ & $10 \%$ & $70 \%$ & $90 \%$ \\
\hline Ср. знач. & 8,5 & 8,5 & 6,5 & 4,3 & 7,4 & 8,8 \\
\hline
\end{tabular}

По такому параметру, как «знакомство с процедурой» $10 \%$ учеников имели низкий уровень готовности, после проведения тренинговых занятий этот процент понизился до 0\%. Стоит отметить, что есть тенденция к повышению результатов по данному показателю. Но при этом с помощью математической обработки данных не было выявлено различий (t эмпирическое $=1,4)$.

При первичной диагностике $60 \%$ учащимся был характерен высокий уровень тревоги, вызванный предстоящими экзаменами. После коррекционной работы данный процент уменьшился до 10\%. Математическая обработка данных подтвердила выявленные различия на пятипроцентном уровне значимости ( $t$ эмпирическое $=2,7)$.

70\% старшеклассникам изначально был свойственен высокий уровень готовности по параметру «самоконтроль и самоорганизация». При повторной диагностике этот процент возрос до 90\%. Как мы видим, имеется тенденция к повышению результатов по этому параметру. При дальнейшей коррекции результаты учащихся могут повыситься. Математическая обработка данных не подтвердила выявленные различия ( $\mathrm{t}$ эмпирическое $=2,2$ ).

Проведенное исследование подтверждает, специ- 
ально разработанная коррекционная программа, которая содержит в себе методы арт-терапии, способствует снижению уровня тревожности старшеклассников перед ЕГЭ.

В настоящее время все чаще обостряется проблема повышения уровня тревожности школьников. Особенно старшеклассников в период подготовки к экзаменам. Поэтому необходимым является проводить коррекционные работы с учащимися с целью снижения уровня тревожности и ее профилактики.

Нами было проведено исследование, в ходе которого осуществлялась диагностика общего уровня тревожности старшеклассников, а также уровня тревожности, вызванной предстоящими экзаменами.

Было выявлено, что большая часть класса имеет высокий уровень тревожности по какому-либо показателю. С данным процентом учеников была проведена коррекционная программа, состоящая из 8-ми занятий продолжительностью в один час. Основной метод, ис- пользующийся в тренингах - метод арт-терапии.

По завершению тренинговых занятий было осуществлено повторное диагностирование с целью сравнения результатов. С помощью t-критерия Стьюдента было выявлено, что практически для всех учеников данная коррекционная программа оказалась эффективной, поскольку уровень их тревожности по различным показателям снизился.

Мы считаем, что необходимым является осуществлять психолого-педагогическое сопровождение старшеклассников на протяжении подготовки к ЕГЭ. Ведь в этот период уровень их стресса и тревоги в разы возрастает, что может привести к пагубным последствиям. А для того, чтобы ученик успешно сдал все экзамены, ему необходима поддержка и помощь со стороны окружающих. Только так старшеклассник сможет быть уверенным в себе, быть мотивированным к деятельности и не испытывать постоянное чувство страха и тревоги. По нашему мнению, метод арт-терапии в тренинге является интересным и эффективным для старшеклассников и может быть использован в работе педагога-психолога.

\section{ЛИТЕРАТУРА}

1. Краткий психологический словарь / под ред. Петровского А.В., Ярошевского М.Г. М.: Академия. 2009. - 432 с.

2. Тревога и тревожность. Хрестоматия / сост. В.М. Астапов. - СПб. 2010. - 143 с.

3. Аверин В.А. Психология детей и подростков. - СПб.: Изд-во Михайлова В.А., 1998. - 379 с.

4. Грановская Р.М. Элементы практической психологии. - СПб.: Речь, 2010. - 39 с.

5. Андреева И.Н. Взаимосвязь личностной тревожности и социально-психологических характеристик подростков: автореферат дисс. канд. психол. наук. Минск, 2012. -21 c.

6. Чибисова М. Методический инструментарий психологической подготовки к ЕГЭ // Народное образование. 2009. № 9. с.197-203.

7. Меттус Е.В. Памятки для подготовки учащихся к ЕГЭ // Справочник классного руководителя. 2014. № 4. - С. $28-34$.

8. Киселева М.В. Арт-терапия в психологическом консультировании: учебное пособие / М.В. Киселева, В.А. Кулганов. - СПб.: Речь, 2014. - 64 с.

9. Психологическое консультирование в школе. Хрестоматия / Сост. Н.В. Коптева. - Пермь: Западно-Уральский учебно-научный центр, 2010. - 220с.

10. Лебедева Л.Д. Практика арт-терапии: подходы, диагностика, система занятий. СПб. Речь, 2013. - 256с. 